\title{
Immediate correction required to expect a long-term effectiveness of a brace treatment: a biomechanical insight
}

\author{
Julien Clin", Carl-Eric Aubin, Hubert Labelle, Stefan Parent \\ From 7th International Conference on Conservative Management of Spinal Deformities \\ Montreal, Canada. 20-22 May 2010
}

\section{Background}

Immediate in-brace correction has often been deemed as fundamental to long-term brace effectiveness but the biomechanical rational is unclear and unproven.

\section{Objective}

To biomechanically study how the immediate in-brace correction of the scoliotic curves is affecting the mechanisms involved in the long term correction of the spine.

\section{Methods}

The three-dimensional geometry of 30 patients was acquired using multi-view radiographic reconstruction and surface topography techniques. A finite element model of the trunk and a parametric brace model were created. For each case, two spinal stiffnesses (flexible, stiff) were tested. Installation of the brace was simulated. Using an experimental design framework including thirteen design factors, 768 braces were tested for each patient (total of 69120 tested braces). Immediate inbrace correction of the coronal Cobb angles and loads acting on the growth plates of the apical vertebrae were computed and analyzed.

\section{Results}

Immediate correction of coronal curves and corresponding bending loads on the apical vertebrae were linearly correlated (mean R2 $=0.86$ ). $10 \%$ to $99 \%$ of immediate correction was necessary to nullify the asymmetric loads, with an average of $49 \%$ (flexible spine model) and $35 \%$ (stiff spine model).

Sainte-Justine Hospital, Montreal, Canada

Full list of author information is available at the end of the article

\section{Discussion}

Based on the Hueter-Volkmann principle, the correlation between immediate in-brace correction and corresponding modification of the load distribution at the apical level contributes to reducing the scoliosis vicious circle. The immediate correction values corroborate the rule-of-the thumb frequently used by the orthotists.

\section{Conclusion}

This study confirms the importance of immediate inbrace correction and provides insights into the understanding of brace biomechanics.

Published: 10 September 2010

doi:10.1186/1748-7161-5-S1-063

Cite this article as: Clin et al.: Immediate correction required to expect a long-term effectiveness of a brace treatment: a biomechanical insight. Scoliosis 2010 5(Suppl 1):063.
Submit your next manuscript to BioMed Central and take full advantage of:

- Convenient online submission

- Thorough peer review

- No space constraints or color figure charges

- Immediate publication on acceptance

- Inclusion in PubMed, CAS, Scopus and Google Scholar

- Research which is freely available for redistribution

Submit your manuscript at www.biomedcentral.com/submit 